\title{
LETTERS
}

\section{Data limitations may affect conclusions in study of vaginal delivery at midpelvic station}

We have read with interest the recent publication of Muraca and colleagues. ${ }^{1}$ The available data did not specifically identify second-stage operative deliveries, so the authors had to exclude the vast majority of deliveries, most critically more than 200000 that did not have adequate documentation of indication for delivery. The cohort was further reduced to only those who had a prolonged second stage and dystocia as the indication for delivery, a minority of the available participants.

Although the data suggest an association between operative vaginal delivery and adverse neonatal outcomes, we do not feel the authors have considered all the potential limitations of their data. The manuscript states that the International Statistical Classification of Diseases and Related Health Problems, 10th revision (ICD-10) codes were validated. However, the two citations provided are for studies that evaluated maternal outcomes; no neonatal outcomes were included. ${ }^{2,3}$ We know of no studies that have evaluated the reliability of the neonatal ICD-10 codes used in this study. This is an important potential issue because it is very likely that pediatricians are more likely to look for cranial trauma in babies who were delivered using forceps than in those who were delivered by cesarean section. Do the authors have any idea of how many of the cases coded for intercranial trauma might just have been suspected trauma?

Neonatal asymptomatic subdural hematoma following all types of delivery is common, ${ }^{4}$ so the possibility of diagnostic suspicion bias should be considered. It is also difficult to evaluate the importance of the birth trauma variable when it included cases of scalp laceration and facial nerve palsy, which are not clinically important. The supplementary data document no statistically significant association between attempted operative vaginal delivery and clinically important outcomes such as intercranial hemorrhage.

\section{Stephen L. Wood MD MSc}

Associate Professor, Departments of Obstetrics and Gynecology, Cummings School of Medicine, University of Calgary, Calgary, Alta.

Cite as: CMAJ 2017 October 30;189: E1343. doi: 10.1503/cmaj.733316

\section{References}

1. Muraca GM, Sabr Y, Lisonkova S, et al. Perinatal and maternal morbidity and mortality after attempted operative vaginal delivery at midpelvic station. CMAJ 2017;189:E764-72.

2. Joseph KS, Fahey J. Canadian Perinatal Surveillance System. Validation of perinatal data in the Discharge Abstract Database of the Canadian Institute for Health Information. Chronic Dis Can 2009;29:96-100.

3. Data quality study of the 2015-2016 Discharge Abstract Database: a focus on hospital harm. Ottawa: Canadian Institute for Health Information; 2016.

4. Whitby EH, Griffiths PD, Rutter S, et al. Frequency and natural history of subdural haemorrhages in babies and relation to obstetric factors. Lancet 2004;363:846-51.

Competing interests: None declared. 